\title{
Development and study of FeWMoCrBC metallic glass coatings synthesized by electrospark deposition
}

\author{
A.A. Burkov ${ }^{\dagger}$ S.A. Pyachin, A.V. Zaytsev, E.A. Kirichenko, M.A. Teslina, N.A. Syuy \\ †burkovalex@mail.ru
}

Institute of Materials of Far Eastern Branch of RAS, 153 Tikhookeanskaya Street, Khabarovsk 680042, Russia

\begin{abstract}
The paper is devoted to studying the possibility of creating an amorphous state in the metallic materials in the electrospark action process. Produced by powder metallurgy FeWMoCrBC crystalline alloys of two different compositions that were used as anodes for the coating onto the steel 1035 substrate by electrospark deposition technology. Study of mass transfer kinetics during the deposition of both compositions showed relatively high values of gain cathodes. Thus, the maximum mass transfer efficiency achieved using an electrode with a high iron content due to better adhesion to the steel substrate. It is found that by coating had a thickness of about 40 microns and had the metallic glasses structure from XRD data. Based on the results of differential scanning calorimetry revealed that recrystallization of the coating material occurred at annealing temperature exceeding $814-825^{\circ} \mathrm{C}$. XRD data of the samples after annealing at $1200^{\circ} \mathrm{C}$ showed that the amorphous structure is crystallized into carbides iron, tungsten and boron; borides iron, molybdenum and tungsten; as well as is observed metallic chromium and tungsten. The surface roughness of coatings was 7 microns. Were conducted tests on the durability of FeWMoCrBC metallic glass coatings to microabrasive wear, and dry sliding abrasion with a silicon carbide abrasive disk. It is shown that the FeWMoCrBC amorphous electrospark coatings improve wear resistance and microhardness of the steel 1035 in $2-4$ times, respectively. In general, despite the significant differences in the composition of the electrode materials obtained from the coating of metallic glasses had very similar properties.
\end{abstract}

Keywords: amorphous alloys, metallic glass, coating, electrospark deposition, wear resistance.

\section{Создание и изучение износостойкости аморфных электроис- кровых покрытий из сплава FeWMoCrBC}

\author{
Бурков А.А. ${ }^{\dagger}$ Пячин С.А., Зайцев А.В., Кириченко Е.А., Теслина М.А., Сюй Н.А. \\ †burkovalex@mail.ru
}

ФГБУН Институт материаловедения Хабаровского научного центра Дальневосточного отделения РАН, 680042 Хабаровск, Россия

Работа посвящена изучению возможности создания аморфного состояния в металлических материалах в процессе электроискрового воздействия. Методом порошковой металлургии получены FeWMoCrBC сплавы двух различных составов, которые использованы в качестве анодных материалов для нанесения покрытий на подожки из стали 35 методом электроискрового легирования. Изучена кинетика изменения масс электродов в процессе осаждения покрытий. Установлено, что при использовании электрода из FeWMoCrBC сплава с более высоким содержанием железа привес катода выше за счет лучший адгезии к стальной подложке. Толщина созданных покрытий составляет около 40 мкм. По данным рентгеновской дифрактометрии покрытия обладают структурой, аналогичной металлическим стеклам. На основе результатов дифференциальной сканирующей калориметрии определено, что материал покрытий начинает кристаллизоваться в процессе нагрева при температурах свыше $781-786^{\circ} \mathrm{C}$. После отжига при температуре $1200^{\circ} \mathrm{C}$ в электроискровых покрытиях наблюдаются карбиды железа, вольфрама и бора; бориды железа, молибдена и вольфрама; а также хром и вольфрам как отдельные фазы. Шероховатость покрытий по критерию Rа была около 7 мкм. Испытания стойкости покрытий из металлических FeWMoCrBC стекол к микроабразивному износу, а также сухому трению об абразивный диск из карбида кремния, показали, что износостойкость аморфных электроискровых покрытий выше износостойкости стали 35 в 2 - 3 раза. В целом, не смотря на существенные различия в составе электродных материалов, полученные покрытия из металлических стекол обладали приблизительно одинаковыми трибологическими характеристиками.

Ключевые слова: аморфные сплавы, металлические стекла, покрытия, электроискровое легирование, износостойкость. 


\section{1. Введение}

Износ, коррозия и разрушение конструкционных материалов в процессе эксплуатации ограничивают срок службы изготовленных из них изделий, что оборачивается экономическими потерями для промышленных предприятий. Для защиты металлических материалов от различных внешних воздействий применяют износостойкие и коррозионно-устойчивые покрытия [1-4]. Аморфные сплавы, которые часто называют «металлическими стеклами», вызывают интерес как материалы, которые могут быть использованы в качестве защитных покрытий $[5,6]$. Согласно эмпирическим правилам А. Иноуэ металлические стекла должны состоять более чем из трех элементов, иметь различия в радиусах атомов главных элементов более $12 \%$, а также обладать отрицательной теплотой смешивания главных компонентов [7]. Данному требованию удовлетворяют металлические стекла на основе железа, которые привлекательны не только из-за высокой твердости, превосходной коррозионной стойкости и хорошей износостойкости, но также из-за относительно низкой стоимости [8]. Аморфное состояние в металлических стеклах на основе железа может быть достигнуто при скоростях охлаждения порядка $10^{3}-10^{4} \mathrm{~K} / \mathrm{c}[8,9]$.

Среди широкого комплекса физико-химических методов нанесения покрытий следует особо выделить технологию электроискрового легирования (ЭИЛ), основанную на явлении электрической эрозии металлов под действием коротких разрядных импульсов с последующим осаждением эродированного материала на поверхность противоположного электрода [10]. Электроискровые покрытия обладают высокой адгезией с металлической подложкой благодаря интенсивному конвективному перемешиванию металлов в расплавленном состоянии. Примеры формирования электроискровых покрытий из металлических стекол представлены в работах $[11,12]$. В качестве анодных материалов были использованы коммерческие объемные металлические стекла на основе титана и циркония, которые ограничены по химическому составу из-за требований к высокой стеклообразующей способности, а также дороги в изготовлении. С учетом того, что в области воздействия коротких низковольтных электрических разрядов скорость охлаждения металлов достигает $10^{5}-10^{7} \mathrm{~K} / \mathrm{c}[13,14]$, поэтому существует принципиальная возможность создания аморфного состояния из расплавов металлов непосредственно в процессе формирования покрытия на катоде, что позволяет значительно расширить диапазон составов осаждаемых металлических стекол. Впервые в работе [15] методом электроискрового легирования были получены аморфные металлические покрытия с использованием кристаллического сплава $\mathrm{Fe}_{48} \mathrm{Cr}_{18} \mathrm{Mo}_{7} \mathrm{~B}_{16} \mathrm{C}_{4} \mathrm{Nb}_{7}$ в качестве электрода. Однако эксплуатационные свойства сформированных слоев изучены не были.

Цель данной работы заключалась в исследовании возможности формирования аморфных покрытий на основе многокомпонентного FeWMoCrCB сплава на среднеуглеродистой стали 35 методом электроискрового легирования, а также в изучении стойкости полученных покрытий к сухому трению и микроабразивному износу.

\section{2. Методика и материалы}

FeWMoCrCB сплавы двух составов были приготовлены методом порошковой металлургии из химически чистых порошков карбонильного железа, вольфрама, молибдена, карбидов хрома и бора. Исходный состав шихты для получения сплавов представлен в таблице 1. Порошки с добавлением изопропилового спирта были смешаны в шаровой планетарной мельнице Retsch PM 400 при скорости вращения 250 об/мин в течение 30 минут. Полученные смеси были пропитаны раствором каучука в бензине и спрессованы на прессе TestPress-250 M при нагрузке $30 \mathrm{\kappa H}$ в форме стержней с размерами $5 \times 5 \times 30$ мм $^{3}$. Спекание порошков осуществлялось в вакуумной печи Carbolite STF при $1200^{\circ} \mathrm{C}$ в течение 8 часов при давлении 10 Па. Созданные электродные материалы были обозначены как Е1 и Е2, а электроискровые покрытия, нанесенные при их использовании, - как С1 и С2, соответственно. Плотность сплава Е1 составила 8,16 г/ $\mathrm{cm}^{3}$, а сплава Е2-9,1 г/ $\mathrm{cm}^{3}$. Электроды-аноды закрепляли на ручной электромагнитный вибратор, который обеспечивал механические колебания частотой 100 Гц и амплитудой порядка 0,5 мм. Покрытия наносили на подложки из стали 35 с площадью поверхности $10 \times 10 \mathrm{Mm}^{2}$, используя электроискровую установку IMES-40, генерирующую импульсы тока амплитудой 110 А, длительностью 0,2 мс и частотой 50 Гц при рабочем напряжении 30 В. Продолжительность электроискровой обработки для каждого образца составляла 5 минут. Для предотвращения окисления металлов область разрядов обдували потоком аргона. Через каждую минуту электроискрового легирования измеряли массу электродов с помощью весов VibraHT с точностью 0,1 мг.

Фазовый анализ полученных покрытий был проведен с применением рентгеновского дифрактометра ДРОН-7 в $\mathrm{Cu}-\mathrm{Ka}$ излучении. В целях идентификации линий рентгенограмм применялись программный пакет PDWin (НПП «Буревестник») и база данных PDF-2 Meждународного центра дифракционных данных (ICDD). Для исследования фазовых превращений при нагреве в диапазоне $20^{\circ} \mathrm{C}-900^{\circ} \mathrm{C}$ в вакууме был использован дифференциальный сканирующий анализатор STA 449 F3 Jupiter. Скорость нагрева была постоянной $20^{\circ} \mathrm{C} /$ мин, аналогично как и в работе [9]. Для измерения микротвердости по методу Виккерса использовали микротвердомер ПМТ-3М с нагрузкой 0,5 Н. Микроабразивная износостойкость и толщина покрытий были определены с помощью трибометра Calotester CSM instruments по схеме «вращающийся шар-плоскость» с применением смеси порошка оксида кремния и минерального масла МС 20 в качестве абразивной суспензии. Шар из оксида алюминия радиусом $R=10$ мм вращался с линейной скоростью 30 м/мин и давил на образец с силой $P=0,07$ Н. Пройденный путь составил $l=250$ м. Каждый эксперимент был повторен 3 раза. Диаметр каждой образованной лунки $(d)$ был определен как среднее из 2 измерений в перпендикулярных направлениях. Износостойкость пропорциональна длине пройденного пути и величине нагрузки, и обратно пропорциональна 
объему образованной лунки $\left(V \approx p d^{4} /(64 R)\right)$.

$$
S=\frac{P \cdot l \cdot R \cdot 64}{\pi \cdot d^{4}} \quad\left[\mathrm{H} \cdot \mathrm{M} / \mathrm{MM}^{3}\right]
$$

Износостойкость покрытий при сухом трении исследована согласно стандарту ASTM G99 - 04. В качестве контртел использовали абразивные диски из карбида кремния. Скорость трения была 0,15 м/с при нагрузке 8 Н. Шероховатость покрытий измерялась на профилометре 296.

Табл. 1. Элементный состав шихты для спекания электродных материалов.

Table 1. The elemental composition of the charge for the sintering of electrode materials.

\begin{tabular}{|c|c|c|c|c|c|c|}
\hline \multirow{2}{*}{$\begin{array}{c}\text { Электроды } \\
\text { Electrodes }\end{array}$} & \multicolumn{6}{|c|}{$\begin{array}{c}\text { Концентрация, ат.\% } \\
\text { Concentration, at.\% }\end{array}$} \\
\cline { 2 - 8 } & $\mathrm{Fe}$ & $\mathrm{W}$ & $\mathrm{Mo}$ & $\mathrm{Cr}$ & $\mathrm{C}$ & $\mathrm{B}$ \\
\hline $\mathrm{E} 1$ & 20 & 10 & 35 & 15 & 12 & 8 \\
\hline $\mathrm{E} 2$ & 30 & 21 & 14 & 15 & 12 & 8 \\
\hline
\end{tabular}

\section{3. Результаты и обсуждение}

Изменения масс анода $\Delta m_{a}$ и катода $\Delta m_{c}$ в зависимости от продолжительности электроискрового нанесения двух разных покрытий из FeWMoCrCB на сталь 35 показаны на рис. 1а. Видно, что в процессе легирования масса обоих анодов непрерывно уменьшалась, а масса катодов росла, что свидетельствует о переносе анодного материала на стальную подложку. Эрозия анода Е2 и привес катода при нанесении покрытия С2 были выше, чем у Е1 и $\mathrm{C} 1$, соответственно, поэтому толщина покрытия С2 больше (таблица 2). Вероятно, это вызвано более высоким содержанием железа в Е1, что способствует лучшему закреплению эродированного материала на катоде, а с другой стороны, составы поверхностных слоев электродов за счет прямого и обратного переноса выравниваются быстрее, и соответственно снижается интенсивность массопереноса в поздние моменты времени. В целом, привес катода при использовании FeWMoCrCB материалов был достаточно высоким, например, он был более чем в два раза выше, по сравнению с осаждением твердого сплава ВК10, при аналогичных режимах [16].

Изучение кинетики изменения масс электродов при ЭИЛ позволяет оценить эффективность массопереноса с анода на катод [17]. Для этого, исходя из экспериментальных данных о привесе катода $\Delta m_{c}$ и эрозии анода $\Delta m_{a}$, определяют коэффициент массопереноса $K_{m}=\Delta m_{c} /\left|\Delta m_{a}\right|$, графики изменения которого в процессе осаждения покрытий $\mathrm{C} 1$ и $\mathrm{C} 2$ показаны на рис. $1 \mathrm{~b}$. Как видно, коэффициент массопереноса не является высоким из-за большой доли эродированного материала, составляет примерно 0,15-0,2 и незначительно (на 10 - 20\%) увеличивается к окончанию 5 мин легирования. Значения $K_{m}$ при электроискровом осаждении покрытия С2 выше, вероятно, за счет лучшей закрепляемости анодного материала Е2 на низкоуглеродистой стали, обусловленной большим содержанием железа.
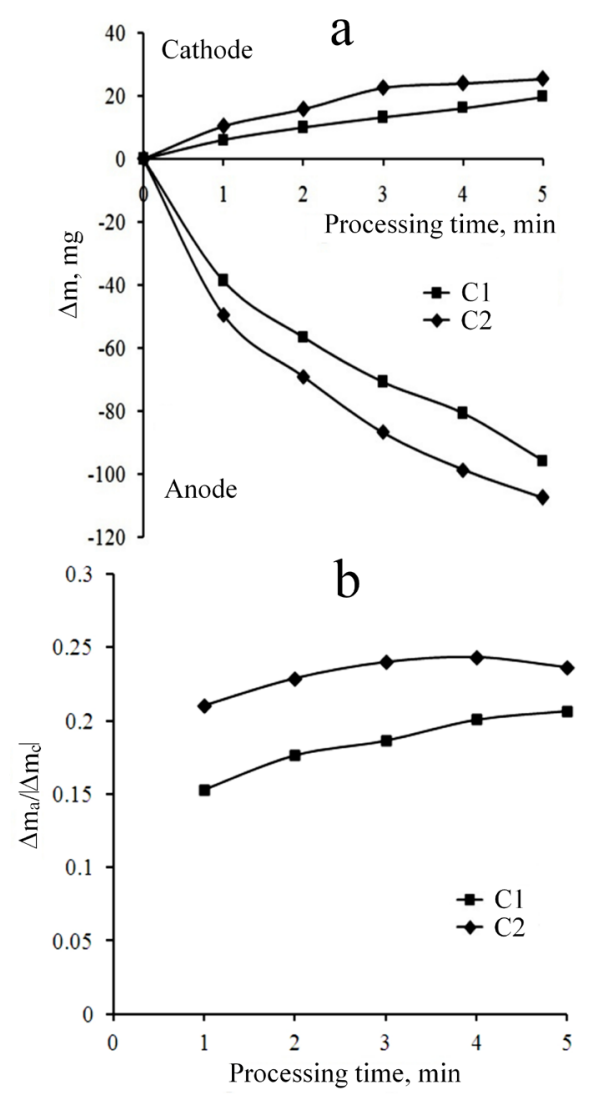

Рис. 1. Изменение масс катода и анода при электроискровом осаждении покрытий из FeWMoCrBC сплавов (a), коэффициент массопереноса (b).

Fig. 1. Cathode mass gain and anode erosion vs processing time at electrospark deposition of FeWMoCrBC coatings (a), mass transfer coefficient (b).

Табл. 2. Свойства покрытий из FeWMoCrBC металлических стекол.

Table 2. Properties of the FeWMoCrBC metallic glass coatings.

\begin{tabular}{|c|c|c|c|}
\hline \multirow{2}{*}{$\begin{array}{c}\text { Characteristic } \\
\text { Характеристика }\end{array}$} & \multicolumn{2}{|c|}{$\begin{array}{l}\text { Coating } \\
\text { Покрытие }\end{array}$} & \multirow{2}{*}{$\begin{array}{c}\text { Substrate } \\
\text { Подложка }\end{array}$} \\
\hline & $\mathrm{C} 1$ & $\mathrm{C} 2$ & \\
\hline $\begin{array}{l}\text { Thickness, } \mu \mathrm{m} \\
\text { Толщина, мкм }\end{array}$ & $39 \pm 11$ & $47 \pm 14$ & - \\
\hline $\begin{array}{c}\text { Roughness } \\
\text { Ra, } \mu \mathrm{m} \\
\text { Шероховатость } \\
\text { Ra, мкм }\end{array}$ & $6,85 \pm 2,5$ & $6,94 \pm 2,1$ & - \\
\hline $\begin{array}{l}\text { Microhardness, } \\
\text { GPa } \\
\text { Микротвер- } \\
\text { дость, ГПа }\end{array}$ & $8,9 \pm 2,1$ & $9,8 \pm 3,1$ & $2,1 \pm 0,13$ \\
\hline $\begin{array}{c}\text { Microabrasive } \\
\text { wear resistance, } \\
\mathrm{N} \cdot \mathrm{m} / \mathrm{mm}^{3} \\
\text { Микроабразив- } \\
\text { ная износостой- } \\
\text { кость, Н·м/мм }\end{array}$ & 537 & 596 & 164 \\
\hline
\end{tabular}


Рентгеновские дифрактограммы FeWMoCrBC покрытий изображены на рис. 2a. На рентгеновских спектрах присутствует широкий дифракционный пик в диапазоне углов $2 \theta=40-50^{\circ} \mathrm{C}$, что указывает на наличие аморфной структуры у материала, перенесенного с анода на катод. В процессе непрерывного нагрева стальных подложек с покрытиями начиная с температур $786^{\circ} \mathrm{C}$ для $\mathrm{C} 1$ и $781^{\circ} \mathrm{C}$ для $\mathrm{C} 2$ присходят структурные изменения сопровождающиеся эндо и экзоэффектами, которые свидетельствует о начале кристаллизации аморфной фазы (рис. 3). После отжига при температуре $1200^{\circ} \mathrm{C}$ на рентгеновских дифрактограммах покрытий появляются линии, соответствующие карбидам и боридам хрома и вольфрама (рис. 2b). В составе покрытия C1 после отжига преобладал сложный борид железа и молибдена $\mathrm{Mo}_{2} \mathrm{FeB}_{2}$, тогда как в покрытии $\mathrm{C} 2$ основную долю составляют карбиды бора, железа и вольфрама, а также борид вольфрама, что объясняется значительно меньшим содержанием молибдена и большей концентрацией вольфрама в электроде Е2.

Для обоих образцов характерно, что микротвердость на различных участках поверхности покрытий примерно одинаковая (таблица 2). Она превышает микротвердость подложки из стали 35 более чем в четыре раза. Вследствие более высокой концентрации вольфрама твердость покрытия С2 выше, чем у С1. Шероховатости Ra изучаемых покрытий практически не отличаются.

Изучение стойкости полученных покрытий к микроабразивному износу показало, что нанесение покрытий из FeWMoCrBC металлических стекол на сталь 35 позволяет увеличить износостойкость стальной подложки более чем в два раза. Износостойкость покрытия С2 выше, чем у покрытия С1 из-за его большей микротвердости (таблица 2). В ходе испытаний покрытий при сухом абразивном трении было установлено, что скорость их износа уменьшается с ростом пути скольжения, тогда как скорость износа стали 35 постоянна (рис. 4). На начальном отрезке пути скольжения (до 500 м) износ покрытий был выше, чем у стали без покрытий, однако суммарный износ за 1260 м пути скольжения у покрытий был в два раза меньше, чем у стали. Высокая скорость износа FeWMoCrBC покрытий на начальном этапе сухого трения обусловлена высокой шероховатостью покрытия. По мере изнашивания площадь истираемой поверхности увеличивалась, а удельная нагрузка износа снижалась. В целом, скорость износа покрытия С2 при сухом трении меньше, чем у покрытия $\mathrm{C} 1$, аналогично как и при микроабразивном износе.

\section{4. Выводы}

Для нанесения электроискровых покрытий были изготовлены электродные материалы из многокомпонентного FeWMoCrBC сплава двух различных составов. Полученные с их использованием покрытия имеют толщину около 40 мкм и обладают аморфной структурой. Микротвердость покрытий из $\mathrm{FeWMoCrBC}$ металлических стекол в 4 раза выше, чем у стальной подложки. Стойкость к сухому и микроабразивному трению превышает сопротивление износу стали 35 более чем в 2 раза. Не-

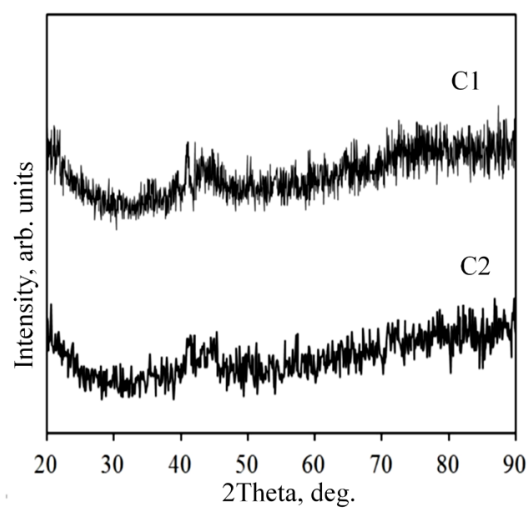

a

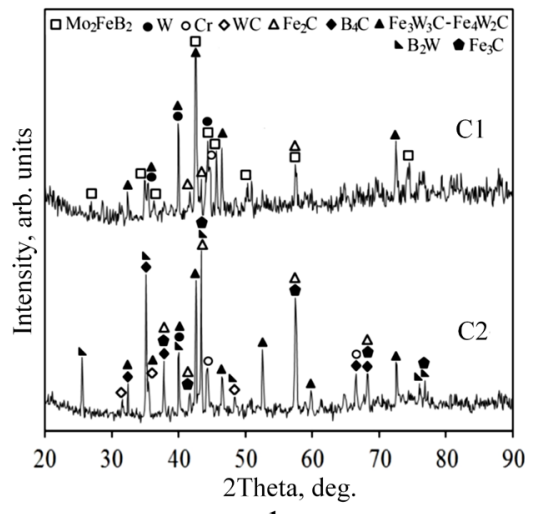

b

Рис. 2. Рентгеновские дифрактограммы покрытий до (а) и после (b) отжига при температуре $1200^{\circ} \mathrm{C}$.

Fig. 2. X-ray diffraction pattern of the coatings before (a) and after (b) annealing at $1200^{\circ} \mathrm{C}$.

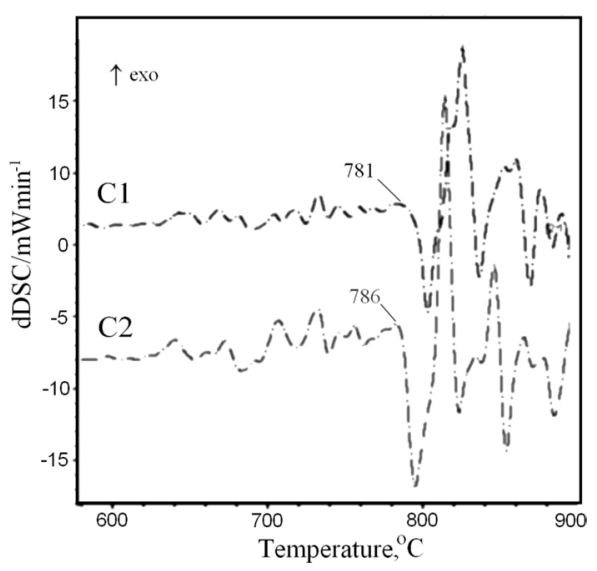

Рис. 3. Производная ДСК кривых для покрытий из металлических стекол.

Fig. 3. The derivative of DSC curves for the metallic glass coatings.

смотря на различия в составе FeWMoCrBC электродных материалов, свойства осажденных покрытий являются практически идентичными. Тем не менее, микротвердость и износостойкость электроискрового покрытия C1 с более высоким содержанием вольфрама и железа, но меньшей концентрацией кобальта, на 10 - 20\% выше, чем, у покрытия С2. Кристаллизация аморфной фазы в покрытиях начинает происходит в процессе нагрева при температурах свыше $781^{\circ} \mathrm{C}$ с выделением карбидов и боридов железа, вольфрама и молибдена. 


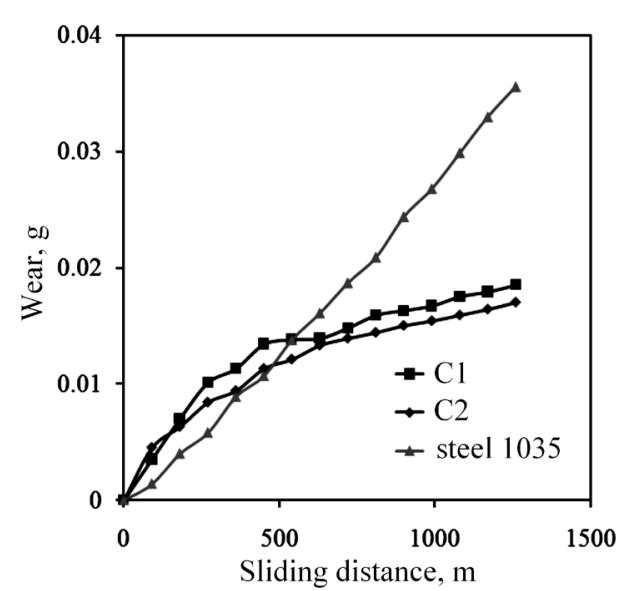

Рис. 4. Убыль массы образцов с покрытиями при сухом трении в сравнении со сталью 35.

Fig. 4. Mass loss of the coated samples during dry sliding wear compared to steel 1035 .

\section{Литература/References}

1. A. Gilewicz, B. Warcholinski. Surf. Coat. Technol. 279, $126-133$ (2015).

2. Z.W. Xie, L.P. Wang, X.F. Wang, L. Huang, Y. Lu, J.C. Yan..Surf. Coat. Technol. 2061293 - 1298 (2011).

3. Minghui Chen, Wenbo Li, MingliShen, Shenglong Zhu, Fuhui Wang Glass - ceramic coatings on titanium alloys for high temperature oxidation protection: Oxidation kinetics and microstructure Corrosion Science 74 (2013) $178-186$.

4. Y. Wang, J. Xiong, J. Yan, H. Fan, J. Wang Oxidation resistance and corrosion behavior of hot-dip aluminized coatings on commercial-purity titanium Surface \& Coatings Technology 206 (2011) 1277- 1282.

5. Han Zhang, Yong $\mathrm{Hu}$, GuoliangHou, Yulong An, Guang Liu The effect of high-velocity oxy-fuel spraying parameters onmicrostructure, corrosion and wear resistance of Fe-based metallic glass coatings // Journal of Non-Crystalline Solids 406 (2014) $37-44$.

6. A. Inoue, Z. Wang, D. V. Louzguine-Luzgin, Y. Han, F.L. Kong, E. Shalaan, F. Al-Marzouki Effect of highorder multicomponent on formation and properties of Zr-based bulk glassy alloys Journal of Alloys and Compounds 638 (2015) 197-203.
7. A. Inoue, Acta Mater. 48 (2000) 279.

8. L. Liu, C. Zhang Fe-based amorphous coatings: Structures and properties // Thin Solid Films 561 (2014) $70-86$.

9. W.-H. Liu, F.-S. Shieu, W.-T. Hsiao Enhancement of wear and corrosion resistance of iron-based hard coatings deposited by high-velocity oxygen fuel (HVOF) thermal spraying // Surface \& Coatings Technology 249 (2014) $24-41$.

10. А. А. Бурков. Повышение жаростойкости титанового сплава ВТ20 путем формирования композиционных электроискровых $\mathrm{Ti}^{3} \mathrm{Al}+\mathrm{Al} / \mathrm{Al}^{2} \mathrm{O} 3$ покрытий. Письма о материалах. 2015. Т.5. № 4. С.371 - 375.

11. C. Li, W. Chen, Q. Jiang, L. Wang, D.Luo. Corrosion resistance of Ti-based metallic glass coating in concentrated nitric acid Materials Chemistry and Physics, 2014, V. 143, P. 900 - 903.

12. Xiang Hong, Yefa Tan, Chunhua Zhou, Ting Xu, Zhongwei Zhang Microstructure and tribological properties of $\mathrm{Zr}$ based amorphous-nanocrystalline coatings deposited on the surface of titanium alloys by Electrospark Deposition. Applied Surface Science, Volume 356, 30 November 2015, Pages $1244-1251$

13. R. N. Johnson, Electrospark deposition: principles and applications, in: Proceedings of the Society of Vacuum Coaters 45th Annual Technical Conference, Lake Buena, Vista, FL, USA, 2002.

14. Q.H. LI, T.M. YUE, Z.N. GUO, and X. LIN. Microstructure and Corrosion Properties of $\mathrm{Al} \mathrm{Co} \mathrm{Cr} F e$ Ni High Entropy Alloy Coatings Deposited on AISI 1045 Steel by the Electrospark Process // Metallurgical and materials transactions A, 2013, V. 44A, P. $1767-1778$.

15. M. Fakoori Hasanabadi, F. Malek Ghaini, M. Ebrahimnia, H.R. Shahverdi Production of amorphous and nanocrystalline iron based coatings by electro-spark deposition process Surface and Coatings Technology 2015, Vol. 270, P. $95-101$.

16. A. A. Burkov, S.A. Pyachin, A.V. Zaytsev, Influence of Carbon Content of WC-Co Electrode Materials on the Wear Resistance of Electrospark Coatings, Journal of Surface Engineered Materials and Advanced Technology, Vol. 2 No. 2, 2012, pp. 65 - 70.

17. A. V. Ribalko, O. Sahin A modern representation of the behaviour of electrospark alloying of steel by hard alloy. Surface and Coatings Technology 2006, Vol. 201, P. $1724-1730$. 